\title{
CIENTIFIQUE-SE
}

Motrivivência Ano XXI, No 32/33, P. 335-343 Jun-Dez./2009

\section{EDUCAÇÃO FÍSICA ESCOLAR: reflexões sobre as aulas de exclusão}

Fabiano Augusto Teixeira?

\begin{abstract}
Resumo Abstract
O objetivo do estudo foi identificar, descrever e interpretar atitudes de exclusão existentes nas aulas de Educação Física e os aspectos que as propiciam. As observações foram realizadas com uma classe de $2^{\circ}$ ano do ensino médio de uma escola particular em Florianópolis, SC. Foi elaborado um roteiro de observação que contemplava possíveis aspectos de exclusão, tanto na prática docente quanto pelos próprios alunos. Os resultados demonstraram como possíveis atitudes de exclusão: relações de gênero com hierarquização do sexo masculino, atitudes competitivas e autoexclusão. Estas se davam por modelos socialmente impostos. Deve-se atentar a estes aspectos e desenvolver The objective of the study was to identify, describe and interpret, attitudes of exclusion existent in Physical Education class and aspects that provide them. The observations were made with a 6 nd grade class of a private school in Florianópolis, SC. Has drawn up a roadmap that included observation of possible aspects of exclusion, both in practice as teachers by the students. The results showed attitudes of exclusion as possible: relations with the gender hierarchy of male, competitive attitudes and self-exclusion. They gave a socially imposed model. You should look to these aspects and develop a physical education in the process
\end{abstract}


uma Educação Física em processo de alteridade, com perspectivas humanistas e interculturais.

Palavras-chave: Educação Física Escolar; Exclusão; Alteridade. of otherness, with humanistic and intercultural perspectives.

Keywords: School Physical Education; Exclusion; Alterity.

\section{Introdução}

A Educação Física teve em sua origem no contexto nacional um caráter biológico, com vistas à eugenia da raça para uma sociedade sadia que atendesse às necessidades solicitadas, restrita à formação de soldados e mulheres aptas à procriação de proles sadias (CASTELLANI FILHO, 2000).

Entre as correntes pedagógicas desse período, que vai até a década de 1980, estão a militarista, a higienista e a recreacionista (DARIDO e SANCHEZ NETO, 2005). Exceto a última, que se caracterizava pela não atuação pedagógica do professor, as demais se caracterizavam por essa visão estritamente biológica do corpo, na qual diferenças encontradas entre indivíduos eram explicadas devido a fatores orgânicos e genéticos, excluindo aspectos socioculturais.

Sob esta ótica era possível solicitar que todos os indivíduos alcançassem o mesmo nível de desenvolvimento, pois havia um padrão mínimo ou esperado e aqueles que estivessem abaixo do padrão, deveriam desenvolver essas solicitações e então alcançar este nível.

A partir da década de 1980 iniciam-se no Brasil discussões sobre novas formas de pensar a Educação Física. Essas buscam relacionar aspectos não apenas biológicos, mas também aspectos socioculturais como determinantes na ação didático-pedagógica do professor.

Entre essas correntes está a Cultural (DAÓLIO, 2003), que propõe a indissociabilidade entre aspectos biológicos e socioculturais nas manifestações corporais na Educação Física. Segundo Daólio (2003, p. 99), a Educação Física deve ser entendida "(...) como uma atuação pedagógica que parte do movimento humano, mas que não se esgota nele".

Entretanto, a bagagem histórica de metodologias e objetivos aplicados à Educação Física, na qual professores quantificam o produto final a ser obtido pelos alunos nas atividades da aula não contribuem para que eles realizem conexões deste conteúdo com sua realidade social. Com isso a disciplina fica desconexa de um contexto e de um objetivo mais amplo.

Além disso, as diferenças entre indivíduos são justificadas 
Ano XXI, n 32/33, junho e dezembro/2009

através de uma condição natural da existência de corpos naturalmente melhores e outros naturalmente piores. Assim a Educação Física escolar se caracteriza pelo caráter de homogeneização (DAÓLIO, 2003). Ainda segundo o autor, esse caráter aplicado a Educação Física escolar buscava retirar a responsabilidade pedagógico-social do educador.

Não se pode realizar uma discussão sobre movimento humano sob uma ótica natural. Toda ação humana é fluentemente influenciada por aspectos culturais e estes são construídos coletivamente, oriundos de um processo de apropriação do corpo pela sociedade na qual o indivíduo está inserido, que manifesta suas particularidades através dele (MAUSS, 1974).

O entendimento do que é cultura é fundamental para prática de uma Educação Física escolar contextualizada e inclusiva (DAÓLIO, 2005; SILVA e SALGADO, 2005). O ser humano é um ser construído culturalmente, desde sua concepção moldado perante a cultura a qual está inserido. Cultura não é elitista, não distingue classes econômicas, muito menos é formal (BRASIL, 1997; CHAUÍ, 2003; DAÓLIO, 2005). Cultura é manifestação humana, é construída, desenvolvida ou moldada através de uma coletividade.
As afirmativas até então expostas buscam refletir sobre um aspecto corriqueiro nas aulas de Educação Física, a exclusão. Atitudes tomadas pelo professor, ações ou falas dos próprios alunos podem contribuir para a exclusão de um, ou vários alunos, em uma aula. Não só o fato de não participar pode ser considerado como exclusivo. Qualquer prática que não tenha um caráter de participação integral e indistinta pode estar gerando atitudes de exclusão (SILVA e SALGADO, 2005).

As autoras afirmam ainda que devam ser implantadas culturas de inclusão e que para isso três idéias centrais são necessárias. Além da primeira já citada, que é o entendimento do que é cultura, deve-se levar em consideração que inclusão não se restringe àqueles com necessidades especiais e que o professor deve ter uma perspectiva humanista, ou seja, enxergar e entender como se dão as relações sociais naquele ambiente e como cada aluno se sente durante esse processo.

Além dessa perspectiva humanista, deve estar presente nas ações do professor a perspectiva intercultural. Ela surge diante de uma pluralidade social, cultural e étnica que compõe a sociedade brasileira (GUSMÃO, 2000). E emerge em um contexto de lutas contra processos de exclusão e valoriza o conflito entre os diferentes como potencial 
educativo para crescimento cultural e enriquecimento de todos (FLEURI, 2000). Com isso diferentes culturas se relacionam, articulando o reconhecimento das identidades étnicas e de gênero.

Com isso, este estudo teve por objetivo verificar possíveis atitudes de exclusão na aula de educação física e discutir os fatores que as envolvem para que haja esclarecimento e auxílio na prática pedagógica do professor através de uma perspectiva humanista e intercultural de Educação Física escolar.

\section{Materiais e métodos}

Este trabalho, caracterizado como um estudo de caso, de caráter exploratório, utilizando-se de dados qualitativos e quantitativos, foi constituído com os alunos do $2^{\circ}$ ano do ensino médio, em uma escola privada em Florianópolis SC, com idade em torno de 17 anos. Não foi observada nenhuma criança que pudesse estar fora deste padrão de idade. A classe caracterizava-se por um número grande de alunos, entre 30 e 35, e nas aulas foi possível verificar a predominância de meninas.

Utilizamos uma observação participante sistemática (Becker, 1997) durante dois meses. Como instrumento para coleta de dados foi utilizado um roteiro de observação com itens abertos e fechados que contemplava os seguintes aspectos: caracterização da escola, da classe observada e das possíveis atitudes exclusivas. Como fatores de exclusão foram considerados: competição, auto-exclusão, exclusão pelo professor, "falta de habilidade", obesidade, status social, estética, motivos de saúde, não compreensão do conteúdo, gênero, deficiência física ou mental, religião, racial e orientação sexual.

Estes foram pré-estabelecidos no instrumento para o pesquisador apenas assinalar se ocorreu ou não. Após constatar algum desses aspectos, era relatado no campo destinado às observações como ocorreu esse processo. Outros motivos não pré-estabelecidos poderiam ser relatados neste mesmo campo destinado às observações.

Este instrumento serviu como apoio para posterior confecção de relatório das aulas. Com as observações realizadas foi possível detectar os seguintes aspectos relacionados à exclusão: gênero, competição e auto-exclusão.

\section{Resultados e Discussões}

\section{As relações de gênero}

Durante as observações das aulas, um aspecto marcante foi à divisão da turma por sexo. Todos os alunos participaram das mesmas atividades, porém os meninos 
eram de uma equipe e as meninas da outra. Foi interessante observar também a forma como se dava essa divisão, existiam momentos que o professor solicitava que a classe se dividisse dessa forma e em outros momentos os próprios alunos a realizavam. Foi necessária também a intervenção do professor em determinados momentos para solicitar que os alunos mesclassem as equipes devido à superioridade da equipe masculina.

Essa divisão parece estar relacionada com o que Heilborn (2006) discute sobre processo de controle social, que influencia as formas como são realizadas as interações corporais. Segundo esse processo, a relação ente sociedade e indivíduo são dependentes de meios ou locais de socialização e a escola é um local propício para o desenvolvimento dessa relação. Porém, a forma como ela será realizada dependerá das influências existentes nesse meio.

Essas influências poderão ser preponderantes na forma como as relações de gênero daqueles alunos serão realizadas posteriormente, pois é provável que aqueles do sexo masculino se vejam com ares de superioridade perante indivíduos do sexo feminino, pois foram socialmente motivados a exercer essa relação de gênero, com a existência de uma hierarquia do sexo masculino.
Quanto a gênero, Grossi (1998, p. 04) define como "(...) formulação ideológica que serve para justificar os comportamentos sociais de homens e mulheres em determinada sociedade." Segundo essa definição a relação de gênero existente naquele contexto era de submissão feminina à superioridade masculina. Superioridade imposta pelas capacidades físicas dos alunos. Não é demais dizer que essa submissão continuará a ser exercida na vida adulta se continuar a ser motivada.

Devreux (2005) denomina esse aspecto como hierarquização de sexo e comenta que ela é socialmente influenciada desde a concepção de uma criança na qual sempre existirá uma dominação por parte dos homens. Atitudes como a relatada apenas corrobora para fortalecer esses ideais, o que poderíamos denominar de dominação e subordinação velada, pois ambos os sexos não se opuseram a essa divisão, inclusive, na segunda aula observada, em que os alunos sugeriram antes mesmo do professor essa divisão foi possível escutar uma declaração de uma menina sobre essa situação: "As meninas ficam com as meninas professor, porque brincar com os meninos é muito chato".

Essa declaração confirma a teoria exposta de dominação de sexo, pois caso alguma menina estivesse no grupo dos meninos não 
seria possível para ela participar da atividade, devido à hierarquia existente de que os meninos seriam superiores e então não contribuíram para que ela participasse. Interessante notar também, através desta declaração, que o fato da atividade ser desenvolvida em uma disputa entre a equipe masculina contra a equipe feminina e esta primeira ter levado vantagem durante sua execução não foi levado em consideração pelas meninas, pois dessa forma era possível para elas, naquele contexto, participar da atividade.

Crianças nesta idade caracterizam-se, segundo a psicologia do desenvolvimento humano, pelo desejo de pertencer a algum grupo, sem fazer referências ao sexo (BECK, 1999), portanto é dever do educador possibilitar que a criança tenha contato com todos a sua volta, indistintamente de sexo, para que não ocorra um fortalecimento da hierarquização imposta e gere conseqüentes atitudes de exclusão e subordinação.

\section{As atitudes competitivas}

O caráter competitivo também ficou evidente durante as observações. Com discussões sobre quem participaria da atividade ou a busca pela individualidade com vistas a vencer a qualquer custo.

Houve também aqueles que, diante de uma atitude de cará- ter lúdico de outro colega durante a realização da atividade, repreenderam a atitude com o comentário: "Ah moleque, presta atenção!".

Quanto a essa situação, os valores atribuídos ao bom se baseiam em padrões distantes da realidade do contexto. Com isso, executar de forma precisa e idêntica a determinado esporte de rendimento parece ser mais atrativo que praticar a atividade com objetivos recreativos, que não seria de tanta importância à precisão e à técnica (SILVA e SALGADO, 2005).

Quanto à faixa etária, os alunos caracterizavam-se por indivíduos capazes de cooperar e trabalhar em conjunto, porém também possuem autonomia pessoal (BECK, 1999). Por isso o professor deve estar atento a esses dois aspectos e fortalecer a linha tênue existente para que os alunos desenvolvam o discernimento necessário sobre como se apropriarem desses dois aspectos.

É necessário também atentar às capacidades físicas de cada aluno e transmitir aos demais alunos o respeito a essas individualidades. Neste caso, uma alternativa possível é a adequação das regras de forma que permita aos menos hábeis igualdade de condições de participação. 
Ano XXI, n 32/33, junho e dezembro/2009

\section{A auto-exclusão}

Outro aspecto presente nas observações foi o da autoexclusão dos alunos. Para melhor entendimento foi estabelecida uma divisão para seus diferentes tipos: auto-exclusão declarada, auto-exclusão não declarada e autoexclusão parcial.

Na primeira categoria, auto-exclusão declarada, foi possível observar uma aluna que indagava sua não participação nas aulas, como demonstra o comentário por ela realizado ao professor: "Professor, não vou fazer aula não!".

Os alunos que realizaram a auto-exclusão não declarada foram aqueles que chegaram antes do professor à quadra e logo em seguida se deslocaram para outro local do colégio sem que o professor notasse. Foi percebido que tal fato acontecia devido à chamada das aulas terem sido realizadas ainda dentro de sala de aula.

$\mathrm{Na}$ terceira categoria, auto-exclusão parcial, encontrava-se os alunos que durante as aulas se isentavam de participar da atividade. Ou seja, estavam presentes, participavam da atividade, porém em determinados momentos isentavam-se da prática, ou cruzando os braços, ou ficando no canto da quadra. Aspectos como o nível de habilidade do aluno, motivação e exclusão pelos mais hábeis podem ter influenciado esse comportamento, porém de forma intrínseca, pois não houve nenhuma demonstração ou manifestação aberta por partes dos alunos para confirmar tal fato.

Pelas experiências e competências pessoais diversificadas, resultante do conhecimento adquirido também fora da escola, não se deve esperar que todos os alunos participem de todas as atividades (BRASIL, 1997).

O professor deverá buscar artifícios pedagógicos que motivem os alunos a estarem presentes e participativos nas aulas, adequando estas ao contexto dos alunos. Ainda segundo os Parâmetros Curriculares Nacionais, favorecer a troca de experiências e estratégias de execução, como a co-educação, em que os mais hábeis auxiliam na aprendizagem dos menos hábeis, são alguns caminhos.

O professor deve estar bastante atento a essas questões e ter subsídios para intervir nos momentos adequados.

\section{Considerações finais}

O ato pedagógico do professor deve focar os diversos fatores que possam resultar em atitudes que levam a exclusão ou inibição dos alunos em relação à participação nas aulas de Educação Física. 
Dentre alguns, podemos citar: uma maior atenção às relações de gênero para que seja possibilitado aos alunos compreender que, independentemente do sexo do indivíduo, homens e mulheres devem desempenhar seus papéis sociais em uma relação de alteridade. Segundo esse princípio o outro existe e está no nosso mundo e o eu no dele. A alteridade revela-se nessa relação, não de tolerância, mas sim de compreensão e igualdade (GUSMÃO, 2000).

Este é um princípio a ser praticado com vistas a contribuir para ações que não gerem exclusão, submissão ou tolerância. Mas sim, respeito mútuo entre os diferentes (GUSMÃO, 2000). A interação com o outro, o diferente, contribui para mudança de compreensão do aluno, que pode assumir papéis e interpretações diferentes nas relações sociais (FLEURI, 2000).

Os processos inclusivos são construídos e não expostos, por isso é de fundamental importância que o professor tenha conhecimento de como se dão estes processos para que sua prática contribua para construção desses valores (SILVA e SALGADO, 2005).

Assim será possível analisar o contexto no qual o aluno está inserido e possibilitará uma prática que não seja alienada, descontextualizada e universal. Devem-se criar culturas de inclusão com vistas ao que o aluno é e independente de diferenças.

Como foi possível perceber, atitudes exclusivas são presentes e em alguns casos não expostas de forma evidente, o que demonstra a importância da discussão das diversas nuances que este tema engloba.

$\mathrm{O}$ recorte realizado nesse estudo, com a observação de poucos meses, de apenas uma classe de uma escola, limita discussões mais amplas, porém instiga a realização de outros estudos com um tempo de acompanhamento das aulas maior e maior aprofundamento no referencial teórico. Isso permitiria discussões mais aprofundadas sobre as atitudes tomadas tanto pelos alunos, quanto pelo professor. $\mathrm{O}$ que possibilitaria entender aquele contexto sob um olhar antropológico mais apurado.

\section{REFERÊNCIAS}

BECK, A. M. B. A psicologia do desenvolvimento. In:

Psicologias. 13. ed. São Paulo:

Saraiva, 1999. p. 97-113.

BECKER, H. Métodos de pesquisas em ciências sociais. São Paulo: Hucitec, 1997.

BRASIL. Secretaria de Educação Fundamental.

Parâmetros 
Ano XXI, n 32/33, junho e dezembro/2009

curriculares nacionais: Educação Física. Brasília: MEC/SEF, 1997. 96p.

CASTELLANI FILHO, L. Educação Física no Brasil: a história que não se conta. 6. ed. Campinas: Papirus, 2000. 225p.

CHAUÍ, M. A cultura. In:

Convite à filosofia. 13. ed. São Paulo: Ática, 2003. p. 288296.

DAOLIO, J. $\boldsymbol{A}$ educação física escolar como prática cultural: tensões e riscos. Revista Pensar a Prática. v. 8, n. 2, p. 215-226, jul./dez. 2005.

\section{A ruptura natureza/} cultura na educação física. In: - Cultura: educação física e futebol. 2 ed. Campinas: UNICAMP, 2003. p. 91-101.

DARIDO, S. C.; SANCHEZ NETO, L. O contexto da Educação Física na escola. In: DARIDO, S. C.; RANGEL, I. C. A. (org). Educação Física na escola: implicações para a prática pedagógica. Rio de Janeiro: Guanabara Koogan, 2005.

DEVREUX, A. A teoria das relações sociais de sexo: um quadro de análise sobre a dominação masculina. Soc. estado. v. 20, n. 3, p. 561-584, dez. 2005.

FLEURI, R. M. Multiculturalismo e interculturalismo nos processos educativos. In.

Ensinar e aprender: sujeitos, saberes e pesquisa. Encontro Nacional de Didática e Prática de Ensino ENDIPE. Rio de Janeiro: DP\&A, 2000. p. 64-81.

GROSSI, M. P. Identidade de gênero e sexualidade. In:

Antropologia em primeira mão.

n. 24. Florianópolis: PPGAS/ UFSC, 1998. p. 1-15.

GUSMÃO, N. M. M. Desafios da diversidade na escola. Revista Meditações, Londrina, v. 5, n. 2, p. 9-28. jul./dez. 2000.

HEILBORN, M. L. Entre as tramas da sexualidade brasileira. Estudos Feministas. Florianópolis, v. 14, n. 1, p. 43-59, jan./abr. 2006. MAUSS, M. Noção de técnica corporal. In.

Sociologia e antropologia. São Paulo: EPU/EDUSP, 1974. p. 211-218.

SILVA, K. R. X.; SALGADO, S. S. Construindo culturas de inclusão nas aulas de educação física numa perspectiva humanista. Arquivos em movimento. Rio de Janeiro, v. 1, n. 1, p. 45-53, jan./jun. 2005.

Recebido: Julho/2010 Aprovado: Agosto/2010 